Review

\title{
Airborne laser scanning of forest resources: An overview of research in Italy as a commentary case study
}

\author{
Alessandro Montaghi ${ }^{\mathrm{a}, *}$, Piermaria Corona ${ }^{\mathrm{b}}$, Michele Dalponte ${ }^{\mathrm{c}}$, Damiano Gianelle $^{\mathrm{c}}$, \\ Gherardo Chirici ${ }^{\mathrm{d}}$, Håkan Olsson ${ }^{\mathrm{a}}$ \\ a Department of Forest Resource Management, Swedish University of Agricultural Sciences, SE-90183 Umeå, Sweden \\ ${ }^{\mathrm{b}}$ Dipartimento per la Innovazione nei Sistemi Biologici, Agroalimentari e Forestali (DIBAF), University of Tuscia, via San Camillo de Lellis, 01100 Viterbo, Italy \\ ${ }^{\mathrm{c}}$ IASMA Research and Innovation Center, Fondazione E. Mach, via E. March 1, 38010 San Michele all'Adige, Trento, Italy \\ ${ }^{\mathrm{d}}$ EcoGeoFor, Laboratorio di Ecologia e Geomatica Forestale, Dipartimento di Scienze e Tecnologie per L'Ambiente e il Territorio, University of Molise, Pesche (Isernia), Italy
}

\section{A R T I C L E I N F O}

\section{Article history:}

Received 25 April 2012

Accepted 4 October 2012

\section{Keywords:}

ALS

LiDAR

Forest inventory

Forest management and planning

\begin{abstract}
A B S T R A C T
This article reviews the recent literature concerning airborne laser scanning for forestry purposes in Italy, and presents the current methodologies used to extract forest characteristics from discrete return ALS (Airborne Laser Scanning) data. Increasing interest in ALS data is currently being shown, especially for remote sensing-based forest inventories in Italy; the driving force for this interest is the possibility of reducing costs and providing more accurate and efficient estimation of forest characteristics. This review covers a period of approximately ten years, from the first application of laser scanning for forestry purposes in 2003 to the present day, and shows that there are numerous ongoing research activities which use these technologies for the assessment of forest attributes (e.g., number of trees, mean tree height, stem volume) and ecological issues (e.g., gap identification, fuel model detection). The basic approaches - such as single tree detection and area-based modeling - have been widely examined and commented in order to explore the trend of methods in these technologies, including their applicability and performance. Finally this paper outlines and comments some of the common problems encountered in operational use of laser scanning in Italy, offering potentially useful guidelines and solutions for other countries with similar conditions, under a rather variable environmental framework comprising Alpine, temperate and Mediterranean forest ecosystems.
\end{abstract}

\section{Contents}

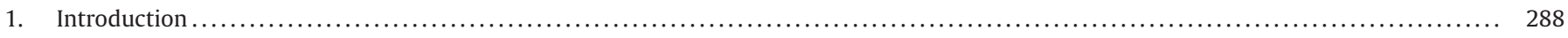

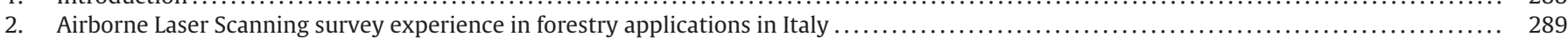

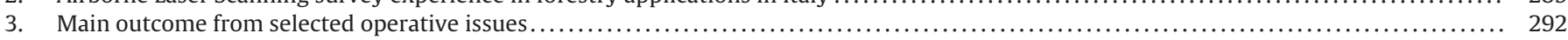

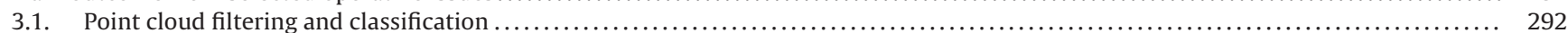

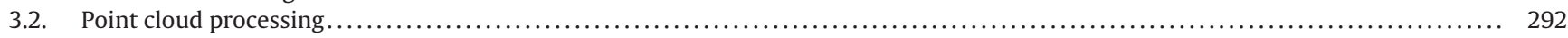

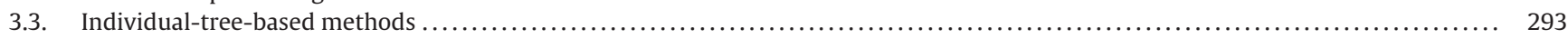

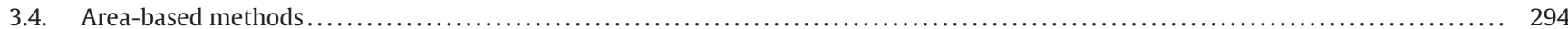

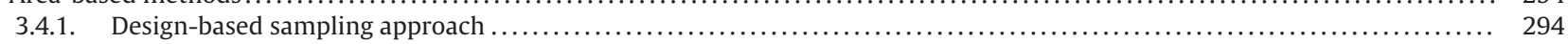

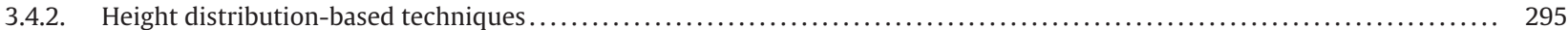

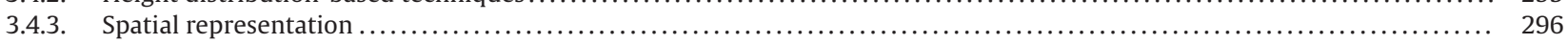

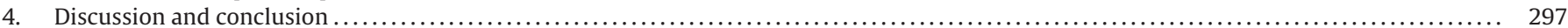

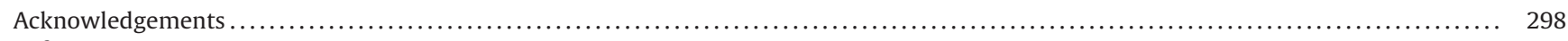

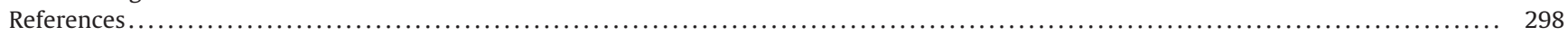

\section{Introduction}

* Corresponding author.

E-mail address: alessandro.montaghi@gmail.com (A. Montaghi).
The increasing availability of data derived from Airborne Laser Scanning (ALS) offers the potential to use this three-dimensional 